\title{
Visual detection of lead(II) using a label-free DNA-based sensor and its immobilization within a monolithic hydrogel
}

\author{
Zachary E. Jacobi, Lu Li and Juewen Liu* \\ Department of Chemistry, Waterloo Institute for Nanotechnology, University of Waterloo \\ Waterloo, Ontario, Canada, N2L 3G1 \\ Email: liujw@uwaterloo.ca
}

Tel: 519-888-4567 ext. 38919

Fax : 519-746-0435

\begin{abstract}
Lead is highly toxic and its detection has attracted a lot of research interests. In recent years, DNA has been used for $\mathrm{Pb}^{2+}$ recognition and many fluorescent sensors with low to sub-nM detection limits have been reported. These figures of merit were typically measured using a spectrophotometer that can detect nM DNA with a high signal-to-noise ratio. For visual detection, however, $\mu \mathrm{M}$ DNA or dye was required, making it difficult to detect low $\mathrm{nM}$ targets. We recently achieved a visual sensitivity of 10 $\mathrm{nM} \mathrm{Hg}^{2+}$ by immobilizing a DNA probe in a hydrogel. This was made possible because the gel was able to actively adsorb $\mathrm{Hg}^{2+}$. In this work, we aim to test whether this method can be extended to the detection of $\mathrm{Pb}^{2+}$. First, a new $\mathrm{Pb}^{2+}$ sensor was designed based on a guanine-rich DNA and DNA binding dyes such as thiazole orange and SYBR Green I. The free DNA showed a detection limit of 8 $\mathrm{nM} \mathrm{Pb}^{2+}$ using $40 \mathrm{nM}$ DNA. For visual detection in solution with $1 \mu \mathrm{M}$ of the DNA probe, however, $\sim 300 \mathrm{nM} \mathrm{Pb}^{2+}$ was required. After immobilization in a monolithic polyacrylamide hydrogel, even 20 $\mathrm{nM} \mathrm{Pb}{ }^{2+}$ could be visually detected with a sample volume of $50 \mathrm{~mL}$. Therefore, sensitive detection
\end{abstract}


without signal amplification was achieved. Finally, we demonstrated simultaneous detection of both $\mathrm{Hg}^{2+}$ and $\mathrm{Pb}^{2+}$ in the same water sample with shape encoded hydrogel sensors.

\section{Introduction.}

Lead is a highly toxic heavy metal that is known to cause a diverse range of adverse health effects, especially to children. ${ }^{1}$ Common symptoms of lead poisoning include mental retardation, behavioral problems, and hearing damage. ${ }^{2}$ To effectively manage the problem of lead contamination, coordinated research efforts have been devoted to the development of sensors that allow on-site and real-time detection. $^{3-5}$ While the current standard for lead analysis still relies on complex analytical instruments such as atomic absorption and emission spectroscopy, these instruments are available only in centralized laboratories, making sensors an attractive alternative.

The use of DNA as a recognition molecule for lead sensing has been extensively explored recently. ${ }^{3,4,6} \mathrm{~Pb}^{2+}$ can act as a highly efficient cofactor to catalyze DNAzyme-based RNA cleavage reactions. ${ }^{7-17}$ In addition, $\mathrm{Pb}^{2+}$ effectively stabilizes the DNA G-quadruplex structure and thus induce a DNA conformational change, ${ }^{18}$ or form a peroxidase DNAzyme in the presence of hemin. ${ }^{19,20}$ The binding affinities between these $\mathrm{DNAs}$ and $\mathrm{Pb}^{2+}$ are in the low $\mu \mathrm{M}$ and even $\mathrm{nM}$ region. A number of signaling methods have been incorporated into these DNAs to result in biosensors with low nM to subnM sensitivity. ${ }^{20-26}$ The maximal contamination level of lead in drinking water defined by the US EPA is $72 \mathrm{nM}$. Therefore, many DNA-based sensors can be potentially used to detect $\mathrm{Pb}^{2+}$ in drinking water.

Most of the reported detection limits were determined using a sensitive fluorometer or spectrophotometer. For practical applications, visual detection with the naked human eye is preferred. Spectrophotometers can detect low nM DNA or fluorophore concentrations with a good signal-to-noise ratio but the human eye requires a concentration of $\sim 1 \mu \mathrm{M}$ or higher. The increase of sensor concentration compromises sensitivity due to the increase of background signal. As a result, few 
sensors can achieve visual detection at low nM target concentration without signal amplification. This is a fundamental issue and thus is true not only for lead detection but also for any other analytes.

We consider that this problem can be solved by sensor immobilization, where a high concentration of DNA probe is fixed onto a surface and target analytes can thus be enriched at the surface through their specific binding. Among the different surfaces available for sensor immobilization, we found that hydrogels are particularly attractive. ${ }^{27}$ Hydrogels have a large loading capacity since immobilization occurs in 3-D. Hydrogels are optically transparent and can be viewed with a very low background color or fluorescence. With the majority of its volume being water, immobilized biomolecules can maintain their native structure and function. Additional advantages of sensor immobilization include sensor regeneration, drying, and signal amplification. ${ }^{28-36}$ We recently reported the immobilization of a $\mathrm{Hg}^{2+}$-binding DNA within a polyacrylamide hydrogel and this sensor can visually detect $10 \mathrm{nM} \mathrm{Hg}{ }^{2+} \cdot{ }^{28,30}$ The DNA formed a hairpin upon $\mathrm{Hg}^{2+}$ binding and in the presence of SYBR Green I (SG) dye, an intense green fluorescence was observed.

In this work, we aim to develop a hydrogel-based fluorescent sensor for visual detection of $\mathrm{Pb}^{2+}$. For signal generation, we plan to employ a label-free design to allow cost-effective detection. There are a number of label-free strategies for $\mathrm{Pb}^{2+}$ detection in the literature ${ }^{20-26}$ but most involve fluorophore generation through catalytic reactions and the generated fluorophores are not bound to the DNA, thus defeating the purpose of sensor immobilization. Therefore, we first designed and characterized a new sensor by screening a number of DNA binding dyes. We found that thiazole orange (TO) and SG can be used for this purpose, both of which showed a yellow-to-green fluorescence change in the presence of $\mathrm{Pb}^{2+}$. After hydrogel immobilization, even $20 \mathrm{nM} \mathrm{Pb}^{2+}$ can be visually detected without any signal amplification procedures. Finally, simultaneous detection of two metals using gel shape to encode for each analyte was also demonstrated. 


\section{Experimental}

2.1. Materials. All the DNA samples were purchased from Integrated DNA Technologies (Coralville, IA) and purified by standard desalting. The sequence of the $\mathrm{Hg}^{2+}$ binding DNA was Acrydite-5'CTTCTTTCTTCCCCTTGTTTGTTG. Acrylamide/bis-acrylamide 29:1 40\% gel stock solution, ammonium persulfate (APS), and N,N,N',N'-tetramethylethylenediamine (TEMED) were purchased from VWR. Malachite green (MG), thiazole orange (TO), zinc protoporphyrin IX (ZnPPIX), mercury(II) perchlorate, lithium chloride, silver nitrate, copper(II) sulfate, zinc chloride, manganese(II) chloride, cobalt(II) chloride, iron(II) chloride, lead(II) acetate, potassium chloride, magnesium chloride, and calcium chloride were obtained from Sigma-Aldrich. Sodium nitrate, ethidium bromide (EB), 2(N-Morpholino)ethanesulfonic acid (MES) and 4-(2-Hydroxyethyl)piperazine-1-ethanesulfonic acid (HEPES) were purchased from Mandel Scientific (Guelph, Ontario, Canada). SYBR Green I, PicoGreen, SYTO-13, and Hoechst 33258 were purchased from Invitrogen (Carlsbad, CA).

2.2. $\mathbf{P b}^{2+}$ detection using non-immobilized DNA. Two conditions with different sensor concentrations were used for $\mathrm{Pb}^{2+}$ detection in solution. First, $40 \mathrm{nM}$ AGRO100 DNA and $20 \mathrm{nM}$ TO were dissolved in $600 \mu \mathrm{L}$ buffer $\mathrm{A}\left(20 \mathrm{mM}\right.$ MES, pH 6.0 and $\left.20 \mathrm{mM} \mathrm{NaNO}_{3}\right)$ in a quartz cuvette. With $510 \mathrm{~nm}$ excitation, emission from 520 to $600 \mathrm{~nm}$ was collected using a Varian Eclipse fluorometer. $\mathrm{Pb}^{2+}$ was titrated from 0 to $130 \mathrm{nM}$. In the second case, $1 \mu \mathrm{M}$ DNA and $0.5 \mu \mathrm{M}$ TO were used in $20 \mathrm{mM}$ MES, pH 6.0, and the measurement was performed using NanoDrop 3300 (Thermo Scientific). For dye screening, the DNA and dye concentrations were both $1 \mu \mathrm{M}$ in a volume of $100 \mu \mathrm{L}$. The $\mathrm{Pb}^{2+}$ concentration was either 0 or $2 \mu \mathrm{M}$. The fluorescence signal was collected using a digital camera (Canon PowerShot SD 1200) under the $254 \mathrm{~nm}$ excitation using a handheld UV lamp.

2.3. Synthesis of DNA-functionalized hydrogels. To prepare the hydrogel the following solutions were mixed: $40 \%$ gel solution (29:1), $\mathrm{NaNO}_{3}(2 \mathrm{M})$, HEPES (pH 7.6, $0.5 \mathrm{M}$ ), acrydite-modified-DNA $(0.5 \mathrm{mM})$, and water. This mixture contained a final gel percentage of $4 \%$ and $100 \mathrm{mM} \mathrm{NaNO}, 50 \mathrm{mM}$ 
HEPES, and $10 \mu \mathrm{M}$ DNA. To initiate polymerization, a fresh initiator solution was made by dissolving $50 \mathrm{mg}$ (APS) in $500 \mu \mathrm{L}$ water and $25 \mu \mathrm{L}$ TEMED. The volume of the initiator was kept to be $5 \%$ of the final mixture. A 96-well plate was used for gel preparation, where $70 \mu \mathrm{L}$ of the gel solution was added to each well. The gels were polymerized for $1 \mathrm{hr}$ at room temperature and then soaked in water twice (each soaking for at least $5 \mathrm{hr}$ ) to remove free monomers, initiator, and unincorporated DNA.

2.4. $\mathbf{P b}^{2+}$ detection using hydrogels. In a typical experiment, each gel was soaked in $1 \mathrm{~mL}$ of buffer $\mathrm{A}$ containing $\mathrm{Pb}^{2+}$ or other metal ions in the presence of $1 \mu \mathrm{M}$ TO. The gel was soaked in this mixture for $1 \mathrm{hr}$ at room temperature on a shaker, excited with a handheld UV lamp at $254 \mathrm{~nm}$ at a distance $\sim 10 \mathrm{~cm}$ from the gel and imaged using the digital camera. A UV protection goggle was used for visual observation. To detect $\mathrm{Pb}^{2+}$ in $50 \mathrm{~mL}$ samples, the gels were soaked in conical tubes containing varying concentrations of $\mathrm{Pb}^{2+}$ and $6 \mu \mathrm{L}$ of $500 \mu \mathrm{M}$ TO. After soaking for $4 \mathrm{hrs}$, the gels were then transferred to $1.5 \mathrm{~mL}$ tubes for imaging.

2.5. Shape encoded detection. A pyramidal mold, with a $7 \times 7 \mathrm{~mm}$ base and a depth of $3 \mathrm{~mm}$ was used to prepare the $\mathrm{Hg}^{2+}$ binding gel. The gel was prepared as above, but with the $\mathrm{Hg}^{2+}$ binding DNA sequence. ${ }^{28}$ For detection, four tubes were prepared containing $10 \mathrm{~mL}$ of buffer $\mathrm{A}$ in the absence or presence of $1 \mu \mathrm{M}$ of $\mathrm{Pb}^{2+}$ or $\mathrm{Hg}^{2+}$. After $1 \mathrm{hr}$ soaking, the gels were transferred into $1.7 \mathrm{~mL}$ microcentrifuge tubes in the same buffer solution and $4 \mu \mathrm{L}$ of $500 \mu \mathrm{M}$ SG was added and the gels were allowed to soak for another $2 \mathrm{hrs}$ before a picture was taken under the $254 \mathrm{~nm}$ UV excitation.

\section{Results and Discussion}

3.1 Sensor design and dye screening. We chose a guanine rich DNA named AGRO100 for $\mathrm{Pb}^{2+}$ recognition. Its sequence is shown in Figure 1A. AGRO100 has been found to be useful for cancer cell inhibition and targeted drug delivery. ${ }^{37}$ Recently, this DNA was also reported to selectively bind $\mathrm{Pb}^{2+}$ with a high affinity and specificity. For example, it was able to bind hemin in the presence of $\mathrm{Pb}^{2+}$ to 
produce a peroxidase DNAzyme, which catalyzed the oxidation of Amplex UltraRed to produce a red fluorescence. ${ }^{20}$ It is generally accepted that the G-quartet formed by AGRO100 consists of a dimer as shown in Figure 1A. To allow effective visual detection, we aim to design a probe that significantly changes the emission property in the presence $\mathrm{Pb}^{2+}$. In particular, the dye should be associated with DNA so that a high optical density can be achieved after DNA immobilization. To this end, we screened the visual response of this DNA in the presence of eight dyes. As shown in Figure 2, most dyes (e.g. SG, PicoGreen, SYTO-13, EB, and Hoechst) showed slightly quenched fluorescence upon addition of $\mathrm{Pb}^{2+}$. ZnPPIX was reported to emit red fluorescence upon binding to another singlestranded G-rich DNA, ${ }^{23}$ but showed no fluorescence with AGRO100. MG is known to bind to Gquadruplex but showed no fluorescence in this case either. ${ }^{38,39}$ Only thiazole orange (TO) produced a comparable fluorescence intensity after adding $\mathrm{Pb}^{2+}$, and this dye is also known to bind to DNA quadruplex..$^{40,41}$ A yellow-to-green fluorescence change was observed for all the green fluorescent dyes. Such a color change is likely to be more visible to the human eye than a small quantum yield change and we chose to use TO and SG for the subsequent studies. 


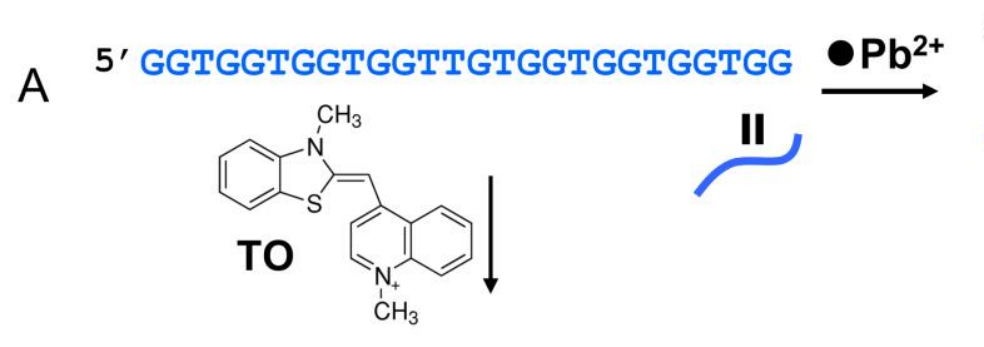

GGTGGTGGTGGTTGTGGTGGTGGTGG

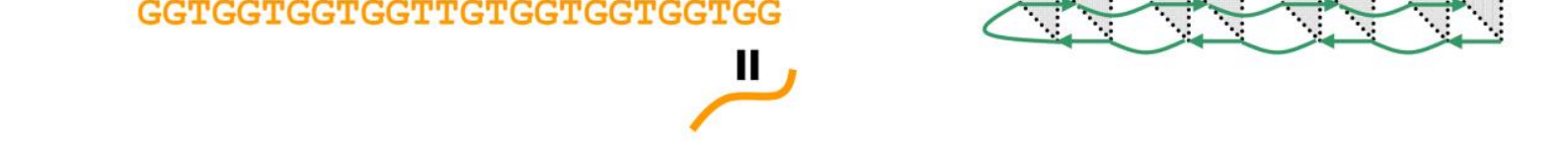

B

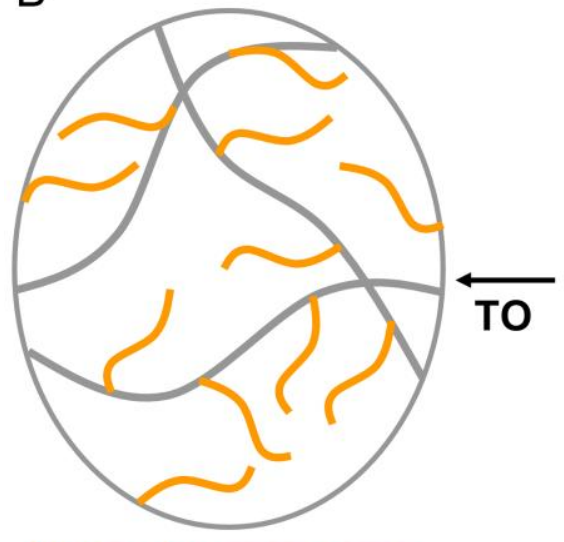

Yellow fluorescence
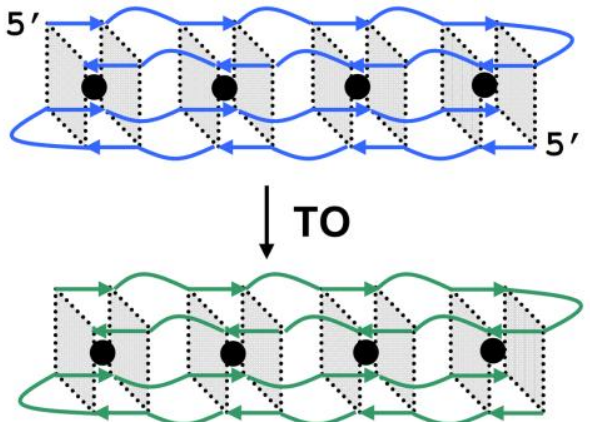

Figure 1. (A) The sequence of AGRO100 and its reaction with $\mathrm{Pb}^{2+}$ and thiazole orange (TO). In the absence of $\mathrm{Pb}^{2+}$, the DNA shows a yellow fluorescence after staining with TO. In the presence of $\mathrm{Pb}^{2+}$, two DNAs assemble to form a quadruplex that emits green fluorescence with TO. The planes connected by the dashed lines represent G-quartets. (B) After covalent immobilization of 5'-acrydite modified AGRO100 within hydrogel, the gel showed yellow or green fluorescence in the absence or presence of $\mathrm{Pb}^{2+}$, respectively. 

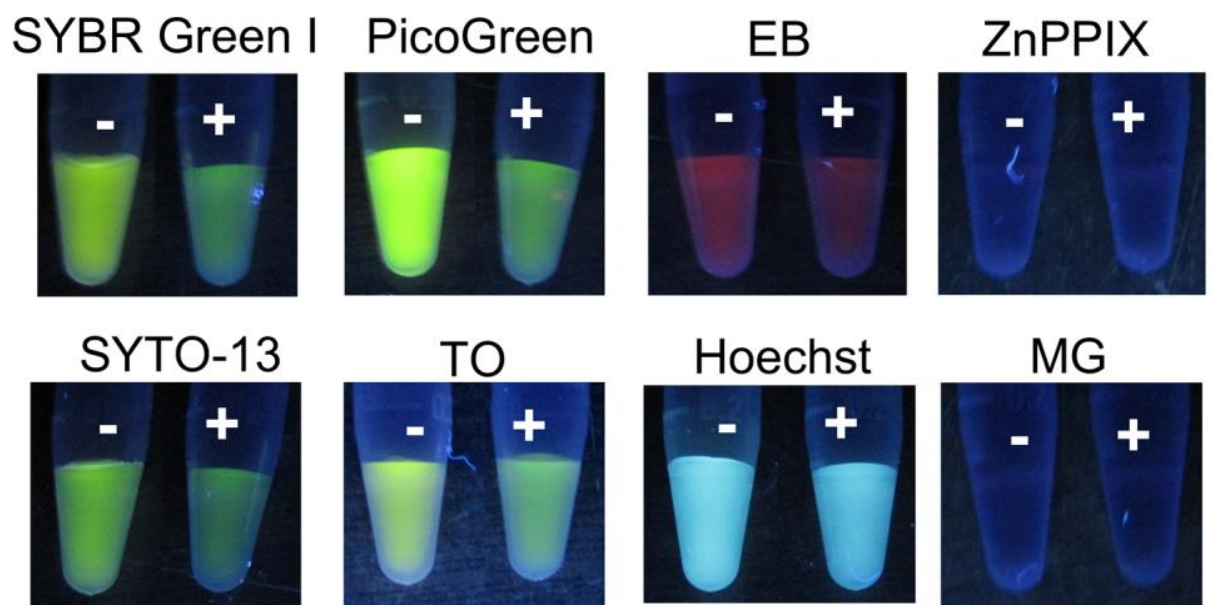

Figure 2. Visual fluorescence observation of eight different DNA binding dyes $(1 \mu \mathrm{M})$ with AGRO100 $(1 \mu \mathrm{M})$ in the presence or absence of $2 \mu \mathrm{M} \mathrm{Pb}^{2+}$. The buffer contained $20 \mathrm{mM} \mathrm{MES}, \mathrm{pH} 6.0$ and 20 $\mathrm{mM} \mathrm{NaNO}$. The pictures were taken under the $254 \mathrm{~nm}$ handheld UV lamp excitation using a digital camera at $\sim 15$ min after adding $\mathrm{Pb}^{2+}$.

3.2. Label free detection. We first tested the sensor performance at a low DNA concentration. With 40 nM AGRO100 and $20 \mathrm{nM}$ TO, an emission peak at $537 \mathrm{~nm}$ was observed under the $510 \mathrm{~nm}$ excitation. Addition of $\mathrm{Pb}^{2+}$ gradually increased the peak intensity and also blueshifted the peak to $531 \mathrm{~nm}$ (Figure 3A), which explained the yellow-to-green color change. The amount of fluorescence increase was only $\sim 60 \%$, which was much lower than that observed for the $\mathrm{Hg}^{2+}$ sensor using $\mathrm{SG}$, where over 10-fold enhancement was achieved. ${ }^{42}$ This suggested that the binding between the DNA and TO was only weakly affected by $\mathrm{Pb}^{2+}$. If the intensity increase was plotted as a function of $\mathrm{Pb}^{2+}$, a sigmoid curve was obtained as shown in Figure 3B, indicative of a cooperative $\mathrm{Pb}^{2+}$ binding. Each pair of DNA can bind to $4 \mathrm{~Pb}^{2+}$ ions considering the formation of four pairs of G-quartets. We achieved a Hill coefficient of 2.7, suggesting that after binding to $3 \mathrm{~Pb}^{2+}$ ions, the structure was stable enough. The initial low $\mathrm{Pb}^{2+}$ concentration part was fit to a linear curve as shown in the inset. The detection limit was calculated to be $8 \mathrm{nM}$ based on $3 \sigma /$ slope calculation, where $\sigma$ is the standard deviation of background fluorescence variation. For comparison, the sensor response in the presence of SG was also measured. As shown in 
Figure 3C, a series of blueshifted spectra with decreasing intensity were obtained, which was consistent with the visual detection results in Figure 2. Therefore, for intensity-based measurement, TO is preferred because of its light-up nature. For wavelength shift (emission color)-based assays, both dyes can be used.
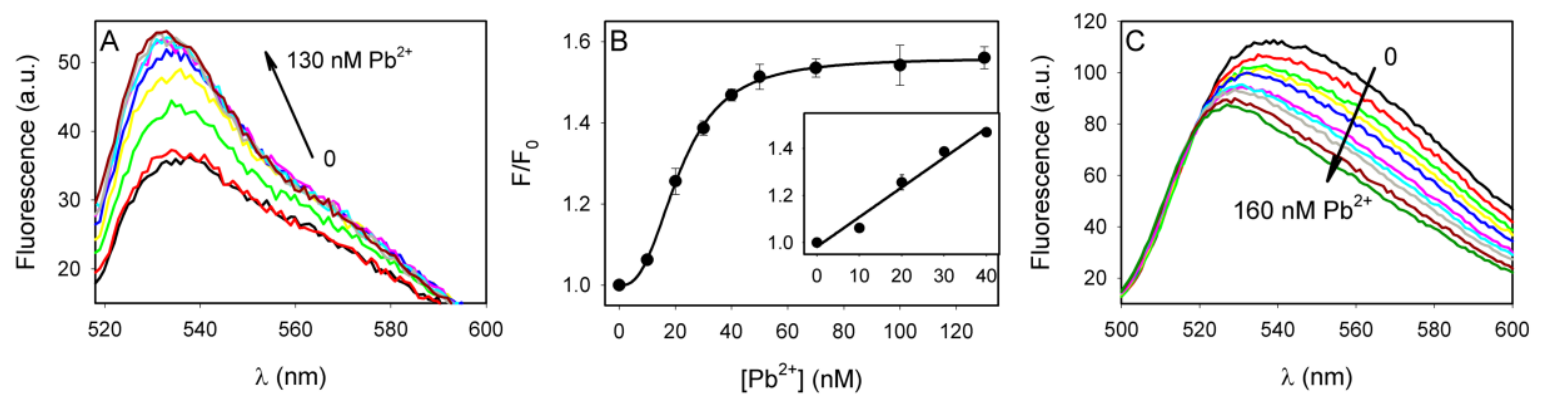

Figure 3. (A) Steady-state fluorescence spectra of the sensor in the presence of varying concentrations of $\mathrm{Pb}^{2+}$ using TO (A) or SG (C) as the DNA staining dye. (B) Fluorescence increase as a function of $\mathrm{Pb}^{2+}$ in the presence of $\mathrm{TO}$. (Inset: response at low $\mathrm{Pb}^{2+}$ concentrations). DNA concentration $=40 \mathrm{nM}$ and dye $=20 \mathrm{nM}$ in $20 \mathrm{mM} \mathrm{NaNO}, 10 \mathrm{mM} \mathrm{MES,} \mathrm{pH} \mathrm{6.0.} \mathrm{The} \mathrm{error} \mathrm{bars} \mathrm{represent} \mathrm{the} \mathrm{standard}$ deviations from three independent measurements.

We next measured the sensor response to other metal ions. As shown in Figure 4A, all the tested competing metal ions $(10 \mu \mathrm{M})$ suppressed the emission intensity and the most significant quenching was observed in the presence of $\mathrm{Cu}^{2+}$, consistent with its paramagnetic nature. Since this sensor is based on the formation of G-quadruplex and $\mathrm{K}^{+}$is also known to be effective for this purpose, we next tested the sensor response in the presence of $\mathrm{K}^{+}$. As shown in Figure 4B, fluorescence increase was not observed until the $\mathrm{K}^{+}$concentration was greater than $1 \mathrm{mM}$, while $100 \mathrm{nM} \mathrm{Pb}^{2+}$ already showed saturated response. It was reported that the quadruplex structure formed in the presence of $\mathrm{Pb}^{2+}$ was tighter than that with $\mathrm{K}^{+}$, explaining the selectivity. ${ }^{19,20,43}$ For comparison, we also titrated the sensor with $\mathrm{Na}^{+}$in the same concentration range and only reduced fluorescence was observed, which 
was attributed to the screening of the attractive electrostatic interaction between TO and DNA. Therefore, this sensor was highly selective for $\mathrm{Pb}^{2+}$.
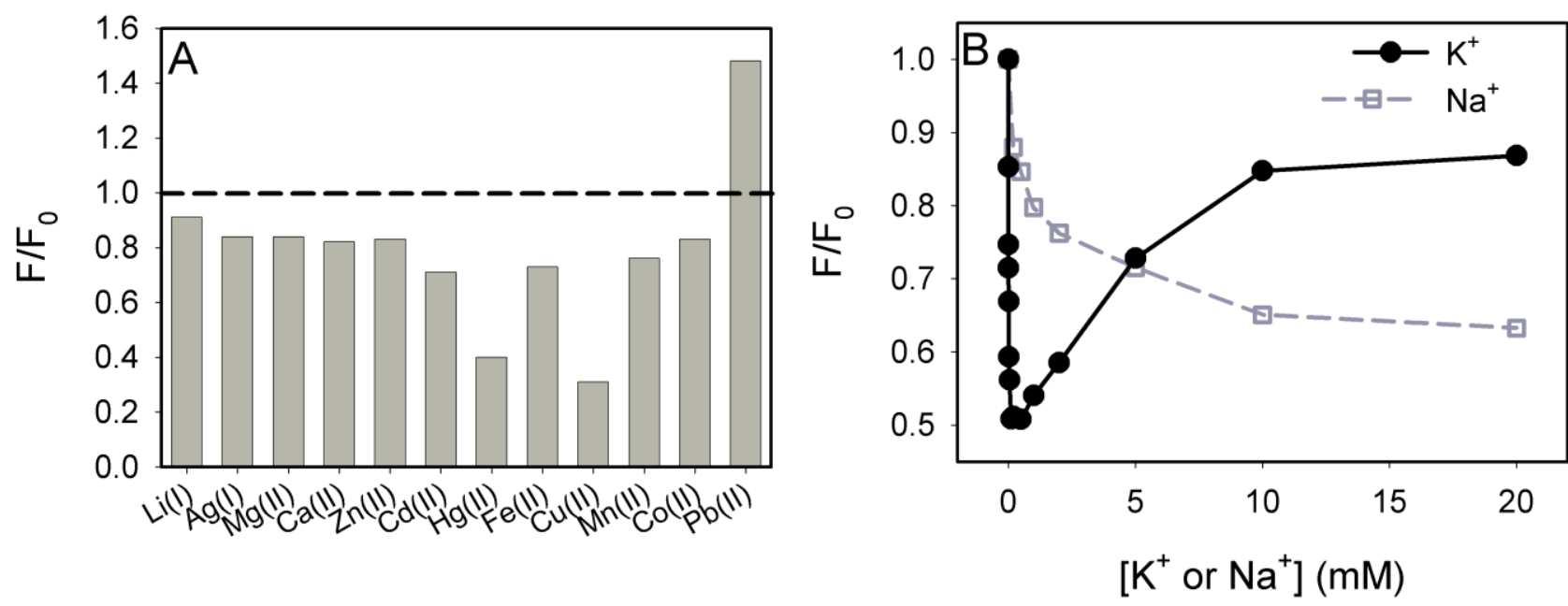

Figure 4. (A) Sensor response in the presence of $10 \mu \mathrm{M}$ competing metal ions or $100 \mathrm{nM} \mathrm{Pb}^{2+}$. Only $\mathrm{Pb}^{2+}$ induced fluorescence increase. (B) Sensor response in the presence of varying concentration of $\mathrm{Na}^{+}$or $\mathrm{K}^{+}$.

3.3. Visual detection. In the above work, a low DNA concentration of $40 \mathrm{nM}$ was used. Its high affinity for $\mathrm{Pb}^{2+}$ allowed highly sensitive detection. To achieve visual detection, the DNA concentration was increased to $1 \mu \mathrm{M}$, while $\mathrm{TO}$ was also raised to $500 \mathrm{nM}$. After this $25 \times$ increase in the probe concentration, a yellow-to-green fluorescence change was observed in the presence of $\mathrm{Pb}^{2+}$

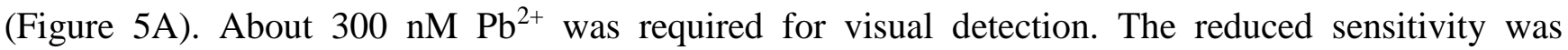
attributed to the increased probe concentration and related high background fluorescence. To have a quantitative understanding, we also performed careful titration studies as shown in Figure 5B for intensity and $5 \mathrm{C}$ for the ratio of intensity at $535 \mathrm{~nm}$ over $539 \mathrm{~nm}$. The intensity did not change significantly when the $\mathrm{Pb}^{2+}$ concentration was below $500 \mathrm{nM}$ while the intensity ratio change was quite 
noticeable at this concentration. Therefore, for such a system with small fluorescence intensity change, the wavelength shift became particularly useful.
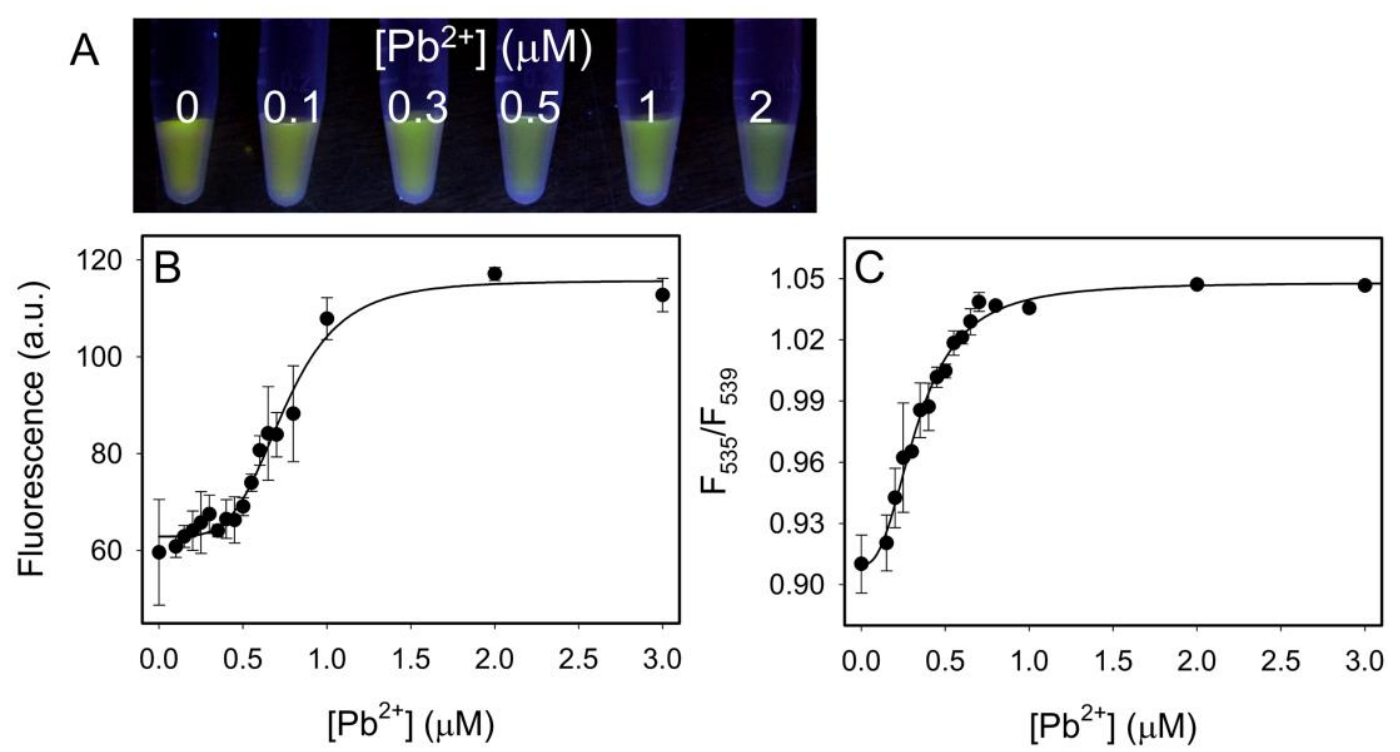

Figure 5. (A) Visual detection of $\mathrm{Pb}^{2+}$ using a digital camera under the UV excitation at $260 \mathrm{~nm}$. Quantification of sensor response in high concentration of DNA (DNA $=1 \mu \mathrm{M}$ and TO $=0.5 \mu \mathrm{M}$ ) using fluorescence intensity (B) or fluorescence intensity ratio (C).

This study also hinted an interesting analytical problem. The human eye is only able to detect changes in fluorescence at high probe concentrations. With the high background associated with high probe concentration, sensitivity is compromised in such a detector limited system. One way to solve this problem is to still use a low probe concentration but introduce a signal amplification mechanism, so that $\mathrm{nM}$ analytes can be amplified through various turnover methods to produce $\mu \mathrm{M}$ fluorophores for detection. ${ }^{13,17,44-47}$ While many elegant designs have been reported, multi-step operations are often required. We chose to use sensor immobilization in hydrogel to achieve analyte enrichment instead of using signal amplification. ${ }^{27,28,30}$ With a high concentration of affinity ligand inside the gel, low 
concentration of $\mathrm{Pb}^{2+}$ can be enriched inside the gel to achieve a high local concentration required for visual detection.

3.4. Acrylamide hydrogel immobilization. To incorporate this DNA into a hydrogel, its $5^{\prime}$-end was labeled with an acrydite group. The gel was prepared using 29:1 acrylamide:bisacrylamide at a final of $4 \%$ with $10 \mu \mathrm{M}$ of the acrydite-modified DNA. After gel formation, the initiators, free monomers, and non-incorporated DNAs were removed by soaking the gels in water. The gels were then exposed to varying concentrations of $\mathrm{Pb}^{2+}$ in a volume of $1 \mathrm{~mL}$ and at the same time $1 \mu \mathrm{M}$ of $\mathrm{TO}$ dye was added. To test the kinetics of signal generation, two gels were soaked in $1 \mathrm{~mL}$ of solution containing either no $\mathrm{Pb}^{2+}$ or $1 \mu \mathrm{M} \mathrm{Pb}^{2+}$. As shown in Figure $6 \mathrm{~A}$, a color difference was observed in just 5 min, although the fluorescence intensity was low. After $1 \mathrm{hr}$, the fluorescence became much brighter and the color difference remained. Therefore we chose to use $1 \mathrm{hr}$ for most of the subsequent experiments. For the non-immobilized sensor, the signal change occurred instantaneously. Therefore, the slow kinetic observed here was due to diffusion within the monolithic gel. To test sensitivity, the gels were exposed to varying concentrations of $\mathrm{Pb}^{2+}$. After soaking for $1 \mathrm{hr}$ at room temperature, the gels were imaged using a digital camera. As shown in Figure 6B, a green fluorescence was observed only in the presence of $500 \mathrm{nM} \mathrm{Pb}^{2+}$, which was similar to the sensitivity for the non-immobilized sensor shown in Figure 5A. Since this DNA can bind $\mathrm{Pb}^{2+}$ with a high affinity, the hydrogel sensitivity may be improved by simply increasing the sample volume. To test this, we soaked the gels in $50 \mathrm{~mL}$ of water samples and found that even $20 \mathrm{nM} \mathrm{Pb}^{2+}$ can be observed by the eye (Figure 6D). This represents the one of the most sensitive $\mathrm{Pb}^{2+}$ sensors using visual detection.

Since hydrogels can be made into different shapes, it is possible to encode for different analytes based on gel shape. ${ }^{36,48,49}$ To test this, we prepared the $\mathrm{Pb}^{2+}$ sensor in a spherical shape and a $\mathrm{Hg}^{2+}$ sensor in a triangular shape. The design of the $\mathrm{Hg}^{2+}$ sensor has been previously reported. ${ }^{28}$ Four water samples were prepared to allow for the testing of all combinations of presence or absence of the two 
metal ions. To each water sample, one $\mathrm{Pb}^{2+}$ detecting gel and one $\mathrm{Hg}^{2+}$ detecting gel was added and after one hour of soaking, SG was added to stain the gels. As can be observed in Figure 6C, each tube contained two gels of different shapes. The round ones were sensitive to $\mathrm{Pb}^{2+}$. Without $\mathrm{Pb}^{2+}$, yellow fluorescence was observed, while green fluorescence was observed in the presence of $\mathrm{Pb}^{2+}$. The triangular gels were used to detect $\mathrm{Hg}^{2+}$ and with $\mathrm{Hg}^{2+}$ very bright green fluorescence was observed. Therefore, simultaneous detection was achieved by hydrogel shapes. We chose to use SG for this experiment because it has been previously used to detect $\mathrm{Hg}^{2+}$.
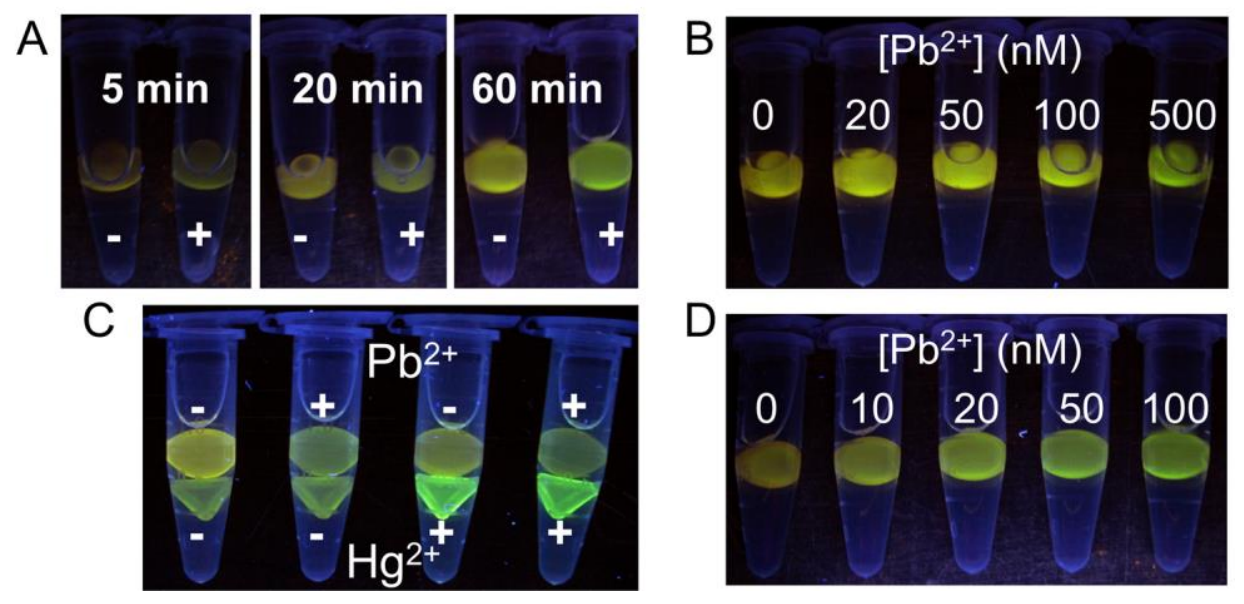

Figure 6. (A) Kinetic of gel fluorescence change in the absence or presence of $1 \mu \mathrm{M} \mathrm{Pb}^{2+}$. Hydrogel sensitivity test using $1 \mathrm{~mL}$ (B) or $50 \mathrm{~mL}$ water sample (D). (C) Gel shape encoded detection. The spherical gels contained the $\mathrm{Pb}^{2+}$ binding DNA and the triangular gels contained the $\mathrm{Hg}^{2+}$ binding DNA. The gels were soaked in the same water samples and stained together by SG. The metal concentrations were 0 or $1 \mu \mathrm{M}$. The image was collected under the excitation of a handheld UV lamp at $254 \mathrm{~nm}$.

\section{Conclusions.}

In summary, we have designed a new label-free sensor for $\mathrm{Pb}^{2+}$ detection using a guanine-rich $\mathrm{DNA}$. This DNA showed a green fluorescence in the presence of $\mathrm{Pb}^{2+}$ and $\mathrm{TO}$, but yellow fluorescence in the absence of $\mathrm{Pb}^{2+}$. Compared to the previously reported label-free sensors for $\mathrm{Pb}^{2+}$ detection, this unique 
wavelength shift allows convenient visual detection. We immobilized the sensor in a polyacrylamide hydrogel and demonstrated that the sensor can detect $\mathrm{Pb}^{2+}$ with a sample volume dependent sensitivity. With a $50 \mathrm{~mL}$ sample volume, even $20 \mathrm{nM} \mathrm{Pb}^{2+}$ can be visually observed. We also demonstrated gel shape encoded detection, suggesting the good generality of the method as well as the potential of detecting a large number of analytes in one pot.

\section{Acknowledgements}

This work is supported by the University of Waterloo, Canada Foundation for Innovation, and the Natural Sciences and Engineering Research Council (NSERC) of Canada. J.L. receives Early Researcher Award from the Ontario Ministry of Research and Innovation.

\section{Bibliographic references and notes}

$1 \quad$ H. L. Needleman, Toxicol.Met., 1996, 405.

2 H. L. Needleman and D. Bellinger, Annual Review of Public Health, 1991, 12, 111.

3 X.-B. Zhang, R.-M. Kong and Y. Lu, Annu. Rev. Anal. Chem., 2011, 4, 105.

4 J. Liu, Z. Cao and Y. Lu, Chem. Rev., 2009, 109, 1948.

5 D. W. Domaille, E. L. Que and C. J. Chang, Nat. Chem. Biol., 2008, 4, 168.

6 Y. W. Lin, C. C. Huang and H. T. Chang, Analyst, 2011, 136, 863.

$7 \quad$ J. Li and Y. Lu, J. Am. Chem. Soc., 2000, 122, 10466.

$8 \quad$ J. Liu and Y. Lu, J. Am. Chem. Soc., 2003, 125, 6642.

9 J. W. Liu and Y. Lu, J. Am. Chem. Soc., 2004, 126, 12298.

10 T. Lan, K. Furuya and Y. Lu, Chem. Comm., 2010, 46, 3896.

11 B. C. Yin, P. Zuo, H. Huo, X. H. Zhong and B. C. Ye, Anal. Biochem., 2010, 401, 47.

12 H. Wang, Y. Kim, H. Liu, Z. Zhu, S. Bamrungsap and W. Tan, J. Am. Chem. Soc., 2009, 131, 8221. 
13 X.-B. Zhang, Z. Wang, H. Xing, Y. Xiang and Y. Lu, Anal. Chem., 2010, 82, 5005.

14 J. W. Liu and Y. Lu, J. Am. Chem. Soc., 2003, 125, 6642.

15 Z. Wang, J. H. Lee and Y. Lu, Adv. Mater., 2008, 3263.

16 H. Wei, B. Li, J. Li, S. Dong and E. Wang, Nanotechnology, 2008, 19, 095501.

17 J. Elbaz, B. Shlyahovsky and I. Willner, Chem. Comm., 2008, 1569.

18 I. Smirnov and R. H. Shafer, J. Mol. Biol., 2000, 296, 1.

19 T. Li, E. Wang and S. Dong, Anal. Chem., 2010, 82, 1515.

20 C.-L. Li, K.-T. Liu, Y.-W. Lin and H.-T. Chang, Anal. Chem., 2011, 83, 225.

21 L. Zhang, B. Han, T. Li and E. Wang, Chem. Comm., 2011, 47, 3099.

22 F. Wang, Z. Wu, Y. Lu, J. Wang, J.-H. Jiang and R.-Q. Yu, Anal. Biochem., 2010, 405, 168.

23 T. Li, S. Dong and E. Wang, J. Am. Chem. Soc., 2010, 132, 13156.

24 C. W. Liu, C. C. Huang and H. T. Chang, Anal. Chem., 2009, 81, 2383.

25 Y. Xiang, Z. D. Wang, H. Xing, N. Y. Wong and Y. Lu, Anal. Chem., 2010, 82, 4122.

26 Y. Xiang, A. J. Tong and Y. Lu, J. Am. Chem. Soc., 2009, 131, 15352.

27 J. Liu, Soft Matter, 2011, 7, 6757.

28 N. Dave, P.-J. J. Huang, M. Y. Chan, B. D. Smith and J. Liu, J. Am. Chem. Soc., 2010, 132, 12668.

29 H. Wang, L. M. L. Ou, Y. Suo and H.-Z. Yu, Anal. Chem., 2011, 83, 1557.

30 K. A. Joseph, N. Dave and J. Liu, ACS Appl. Mater. Inter., 2011, 3, 733.

31 T. S. Dalavoy, D. P. Wernette, M. J. Gong, J. V. Sweedler, Y. Lu, B. R. Flachsbart, M. A. Shannon, P. W. Bohn and D. M. Cropek, Lab Chip, 2008, 8, 786.

32 D. P. Wernette, C. Mead, P. W. Bohn and Y. Lu, Langmuir, 2007, 23, 9513.

33 D. P. Wernette, C. B. Swearingen, D. M. Cropek, Y. Lu, J. V. Sweedler and P. W. Bohn, Analyst, 2006, 131, 41.

34 A. Baeissa, N. Dave, B. D. Smith and J. Liu, ACS Appl. Mater. Inter., 2010, $2,3594$. 
D. C. Pregibon and P. S. Doyle, Anal. Chem., 2009, 81, 4873.

D. C. Pregibon, M. Toner and P. S. Doyle, Science, 2007, 315, 1393.

T. Li, L. L. Shi, E. K. Wang and S. J. Dong, Chem. Eur. J., 2009, 15, 1036.

D. M. Kong, Y. E. Ma, J. Wu and H. X. Shen, Chem. Eur. J., 2009, 15, 901.

A. C. Bhasikuttan, J. Mohanty and H. Pal, Angew. Chem. Int. Ed., 2007, 46, 9305.

40

I. Lubitz, D. Zikich and A. Kotlyar, Biochemistry, 2010, 49, 3567.

41

D. Monchaud, C. Allain and M. P. Teulade-Fichou, Nucleos. Nucleot. Nucl., 2007, 26, 1585.

42

J. Wang and B. Liu, Chem. Comm., 2008, 4759.

43

T. Li, E. Wang and S. J. Dong, Chem. Comm., 2009, 580.

44

D. Li, A. Wieckowska and I. Willner, Angew. Chem. Int. Ed., 2008, 47, 3927.

B. Shlyahovsky, D. Li, Y. Weizmann, R. Nowarski, M. Kotler and I. Willner, J. Am. Chem. Soc., 2007, 129, 3814.

D. Li, B. Shlyahovsky, J. Elbaz and I. Willner, J. Am. Chem. Soc., 2007, 129, 5804.

W. Zhao, M. M. Ali, M. A. Brook and Y. Li, Angew. Chem., Int. Ed., 2008, 47, 6330.

J. E. Meiring, M. J. Schmid, S. M. Grayson, B. M. Rathsack, D. M. Johnson, R. Kirby, R.

Kannappan, K. Manthiram, B. Hsia, Z. L. Hogan, A. D. Ellington, M. V. Pishko and C. G. Willson, Chem. Mater., 2004, 16, 5574.

E. Jang and W.-G. Koh, Sensor. Actuat. B-Chem., 2010, 143, 681. 